\title{
Two Cases of Cerebral Air Embolism That Occurred during Esophageal Ballooning and Endoscopic Retrograde Cholangiopancreatography
}

\author{
Suyeon Park', Ji Yong Ahn ${ }^{1}$, Young Eun Ahn ${ }^{1}$, Sang-Beom Jeon², Sang Soo Lee ${ }^{1}$, Hwoon-Yong Jung ${ }^{1}$ and Jin-Ho Kim ${ }^{1}$ \\ Departments of ${ }^{1}$ Gastroenterology and ${ }^{2}$ Neurology, Asan Medical Center, University of Ulsan College of Medicine, Seoul, Korea
}

Cerebral air embolism is an extremely rare complication of endoscopic procedure and often life threatening. We present two cases of cerebral infarction due to air embolization caused by an endoscopic intervention. The first case occurred during esophageal balloon dilatation for the treatment of a stricture of an anastomosis site in a 59-year-old man and the second case occurred during endoscopic papillary balloon dilatation in a 69-year-old man who had distal common bile duct stones. After the procedure, cardiopulmonary instability and altered mental status were observed in both patients, and cerebral air embolism was diagnosed in both cases. Hyperbaric oxygen therapy was started in the first case, and high $\mathrm{FiO}_{2}$ therapy was applied in the second case. Although this complication is rare, patient outcomes can be improved if physicians are aware of this potential complication, and immediately begin proper management.

Clin Endosc 2016;49:191-196

Key Words: Intracranial embolism; Embolism, air; Endoscopy

\section{INTRODUCTION}

Gastrointestinal endoscopy has become a routine medical procedure for diagnostic and therapeutic purposes in many diseases. As the number of cases needing an endoscopic procedure has increased, the incidence of various complications have also increased, making their proper management more important. $^{1-4}$

Air embolism is a very rare endoscopic complication that manifests with cardiopulmonary instability and neurologic symptoms. However, because of similar symptoms, it is difficult to distinguish cerebral infarction from sedative-related

Received: April 30, 2015 Accepted: June 22, 2015

Correspondence: Ji Yong Ahn

Department of Gastroenterology, Asan Digestive Disease Research Institute, Asan Medical Center, University of Ulsan College of Medicine, 88 Olympic-ro 43-gil, Songpa-gu, Seoul 05505, Korea

Tel: +82-2-3010-5667, Fax: +82-2-476-0824, E-mail: ji110@hanmail.net

(cc) This is an Open Access article distributed under the terms of the Creative Commons Attribution Non-Commercial License (http://creativecommons.org/ licenses/by-nc/3.0) which permits unrestricted non-commercial use, distribution, and reproduction in any medium, provided the original work is properly cited. complications and, owing to its rarity and the unexplained mechanism involved, physicians rarely suspect brain damage induced by air embolism.

We here report our experiences with two adult cases of cerebral air embolism after endoscopic procedures-esophageal balloon dilatation and endoscopic papillary balloon dilatation (EPBD)—and their clinical outcomes.

\section{CASE REPORTS}

\section{Case 1}

A 59-year-old man presented with a 4-week history of progressive dysphagia. He had undergone a total gastrectomy with D2 dissection 2 years previously for gastric cancer, and the pathologic stage was T3N0M0. Two months after the operation, bone metastasis was found and chemotherapy was applied with S-1 (an oral fluorouracil chemotherapeutic agent). On admission, he had an Eastern Cooperative Oncology Group performance status of 3 and was restricted to a liquid diet. An esophagogastroduodenoscopy revealed a benign 

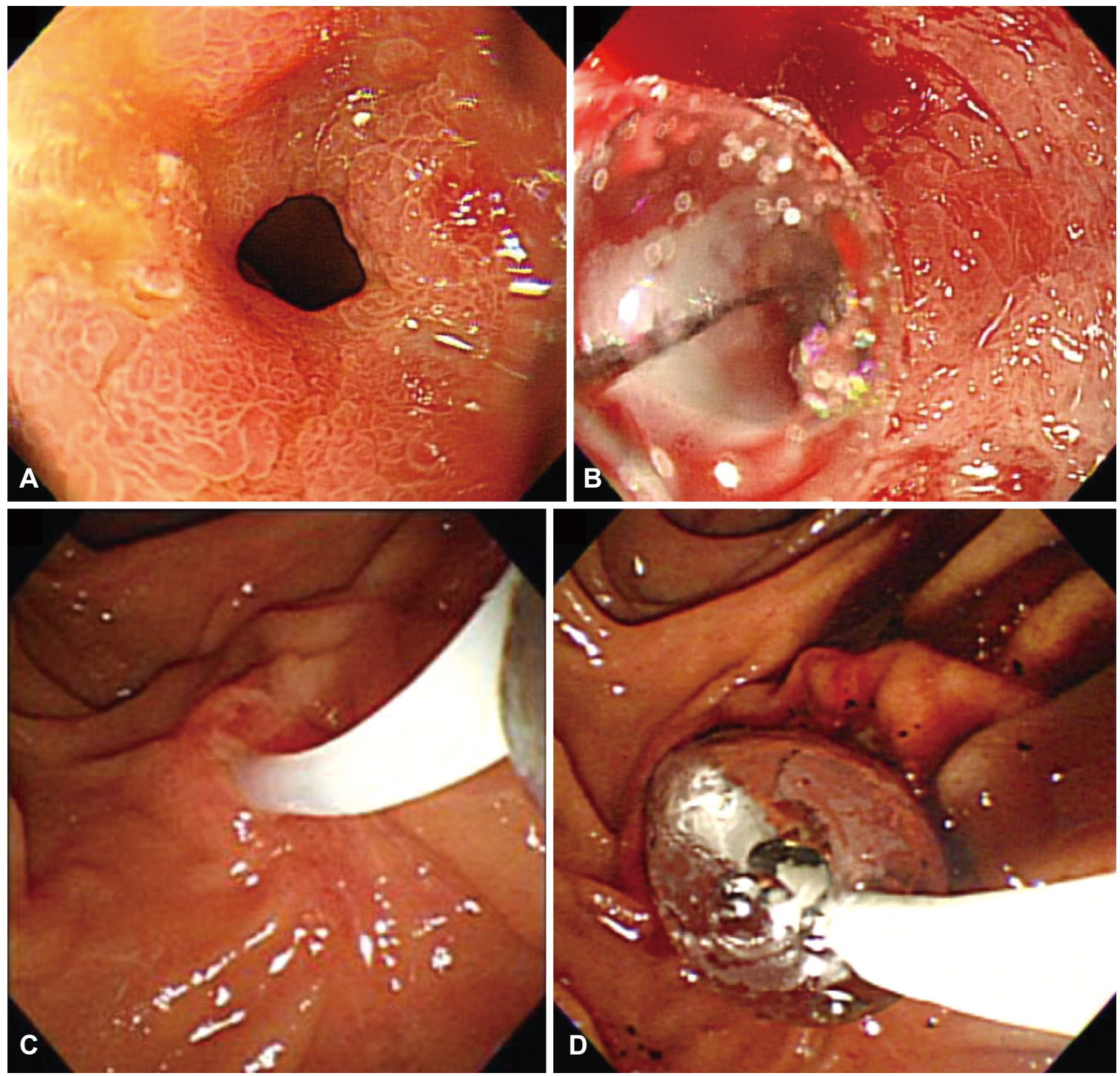

Fig. 1. Endoscopic procedures for the study patients. (A, B) Through-the-scope balloon dilatation was performed in case 1, and (C, D) endoscopic retrograde papillary drainage in case 2. (A) An initial esophagogastroduodenoscopy showed an esophageal stricture at the esophagojejunostomy anastomotic ring. (B) Through-thescope balloon dilatation was performed. (C) Endoscopic biliary cannulation was carried out through the major papilla. (D) Endoscopic retrograde papillary drainage with ballooning was performed.

esophageal stricture at the esophagojejunostomy anastomotic ring (Fig. 1A). Endoscopic balloon dilatation was chosen to achieve proper nutritional support.

This procedure was performed under sedation with intravenous midazolam $(2 \mathrm{mg})$ and with constant vital sign monitoring. His vital signs were stable during the procedure, and through-the-scope ballooning was performed with a CoverEdge wire-guided balloon dilatation catheter (Boston Scientific, Cork, Ireland) under the following conditions: to $8 \mathrm{~mm}$ for 30 seconds with 3 atmospheric pressure, $9 \mathrm{~mm}$ for 60 seconds with 4 atmospheric pressure, and $10 \mathrm{~mm}$ for 60 seconds with 9 atmospheric pressure (Fig. 1B). After the procedure was completed, he became unresponsive (Glasgow coma scale,
3/15), hypotensive (systolic blood pressure/diastolic blood pressure, 66/41 mm Hg), and hypopneic (respiratory rate, 10 breaths per minute).

His vital signs stabilized after $\mathrm{O}_{2}$ was supplied through a venture mask $\left(\mathrm{FiO}_{2} 50 \%\right)$, and after fluid resuscitation and flumazenil injection. However, his altered mental status was not reversed after flumazenil injection.

To determine the cause of the mental change, magnetic resonance imaging (MRI) and brain computed tomography (CT) were performed (Fig. 2), and multiple cerebral infarctions due to air embolism were found. Intubation was performed to increase the $\mathrm{O}_{2}$ supply. Three hours after the procedure, hyperbaric therapy was applied. The therapy was instituted at 

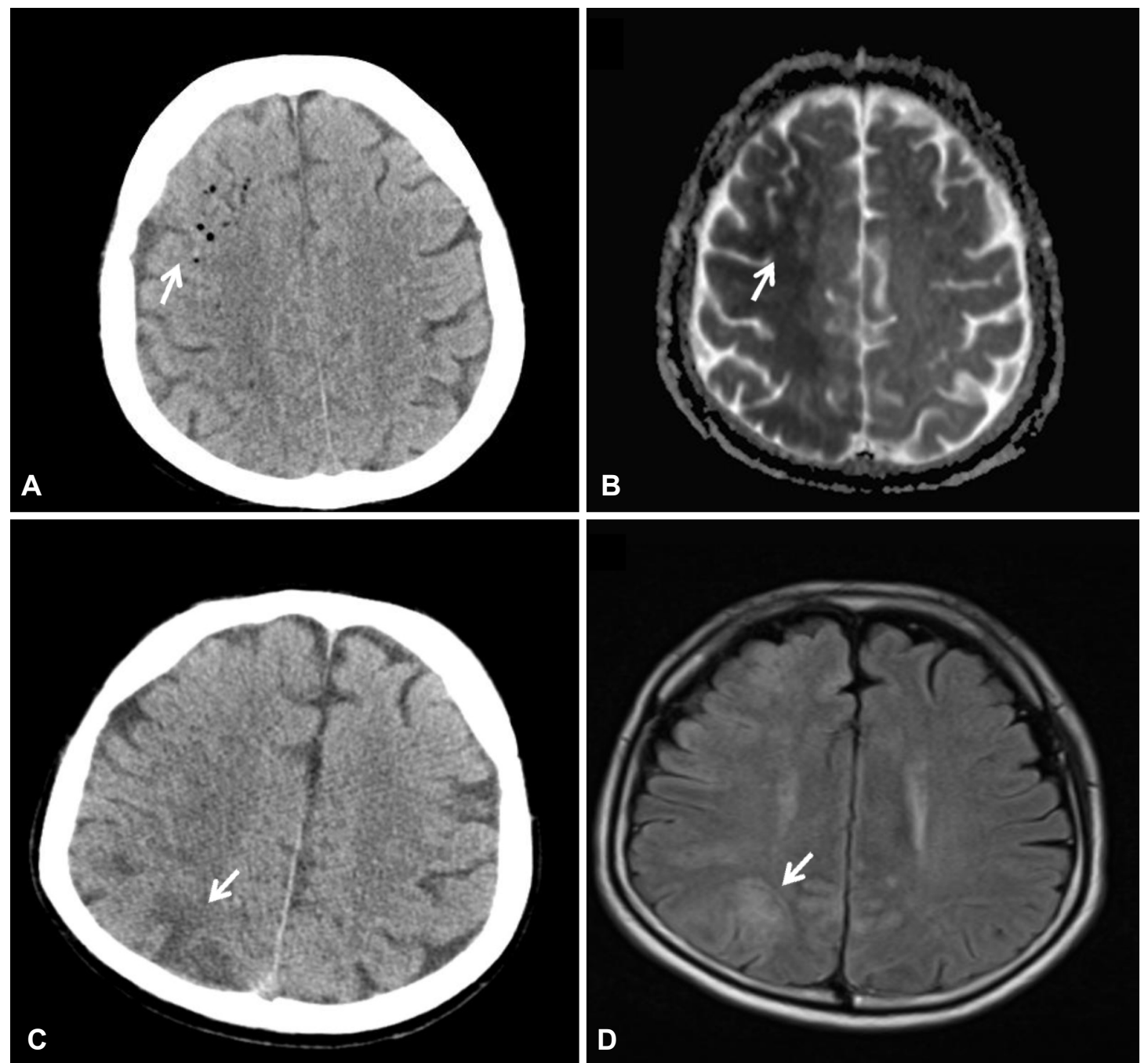

Fig. 2. Imaging studies with computed tomography (CT) and magnetic resonance imaging (MRI). (A) CT scan showing hypodense lesions indicative of air bubbles that were seen predominantly in the right hemisphere in case 1 (arrow). (B) Diffusion-weighted imaging showing diffusion restriction in the right hemisphere in case 1 (arrow). (C) MRI scan showing multiple wedge-shaped low-density regions in the right hemisphere in case 2 (arrow). (D) MRI scan showing multiple diffusion-restricted lesions and fluid-attenuated inversion recovery changes in case 2 (arrow).

3 atmospheric pressure for 2 hours 45 minutes, and gradual decompressed was performed for 1 hour 5 minutes. After hyperbaric therapy, the embolism had nearly disappeared in the follow-up MRI and the vital signs had stabilized. Extubation was performed 4 days after the event, and left-sided weakness remained. Twelve months after the event, he still undergoes rehabilitation treatment for left-sided hemiparesis; however, he can ambulate with minimal assistance.

\section{Case 2}

A 69-year-old man was admitted to our hospital with persistent right upper quadrant pain since 2 weeks. Abdominal CT showed distal common bile duct stones, and he underwent therapeutic endoscopic retrograde cholangiopancreatography (ERCP) under sedation with intravenous midazolam (2 $\mathrm{mg}$ ). His vital signs were stable during the procedure. Multiple filling defects were found, and EPBD was performed to avoid bleeding due to pericholedochal varices. Multiple stones were removed with a hurricane balloon dilatation catheter (Boston Scientific) (Fig. 1C, D), and a fully covered metal stent was inserted to compress the varices.

After ERCP, he became unresponsive (Glasgow coma scale, $3 / 15)$ and hypoxic $\left(\mathrm{SpO}_{2}, 80 \%\right)$. He subsequently became hypotensive and bradycardic, and finally progressed into pulseless electrical cardiac arrest. Cardiopulmonary resuscitation was carried out for 7 minutes before spontaneous circulation was recovered. An imaging evaluation was then performed to determine the cause of the event. Brain MRI and brain CT showed multiple cerebral infarctions (right middle, left anterior, and left posterior cerebral artery territories); however, the images could not distinguish air embolism from other causes. Cholangiography taken during the procedure showed 


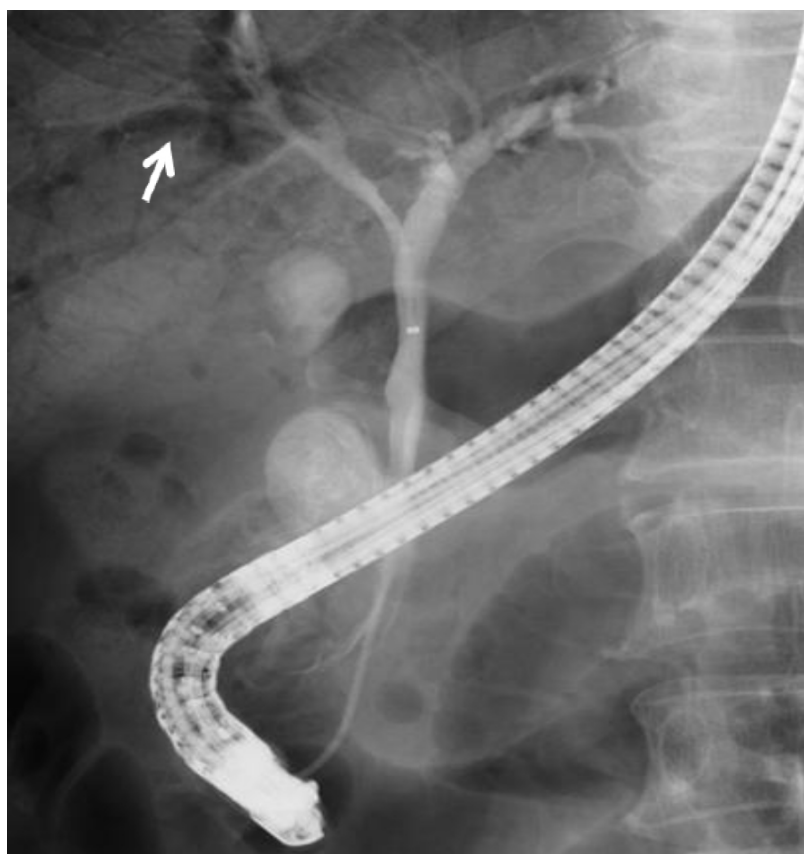

Fig. 3. Endoscopic retrograde cholangiography showing extensive air in the portal vein in case 2 (arrow).

air within the portal veins (Fig. 3), and air embolism could be diagnosed clinically. High $\mathrm{FiO}_{2}$ therapy was provided, and low-molecular-weight heparin was used because other infarction causes could not be ruled out.

After 4 days, the patient's mental status was restored and he was extubated. He underwent rehabilitation treatment for left-sided weakness, and the neurologic deficit improved considerably. Recently, at 2 months after the event, he is able to perform normal activities of daily living.

\section{DISCUSSION}

We here present two cases of cerebral air embolism as a rare complication of therapeutic endoscopy. Rapid diagnoses and prompt treatments were performed in both patients, who both survived. However, the first patient now has a persistent left-sided hemiparesis. In our experience, early suspicion and proper management of air embolism can improve clinical outcomes, although cerebral infarction due to air embolism is an extremely rare and unexpected complication that cannot be completely explained and typically has a poor prognosis.

The mechanism of cerebral air embolization during therapeutic endoscopy is unclear. In theory, the volume of air and rate of accumulation is important in determining the morbidity and mortality after a vascular air embolism develops. A large volume $(\sim 5 \mathrm{~mL} / \mathrm{kg})$ or rapid entry of gas migrating to the pulmonary circulation places strain on the right ventricle. As the pulmonary arterial pressure increases, the left ventricular preload decreases. This situation results in diminished cardiac output that leads to cardiovascular collapse and cerebral hypoperfusion. Venous gas embolism may migrate to the systemic circulation through a shunt such as a patent foramen ovale. However, it has been reported that a large volume of venous gas can enter the arterial circulation through transpulmonary passage of air, without cardiac defects or shunt. The air of the venous circulation enters the arterial systemic circulation and obstructs the end artery, which is a paradoxical embolism. ${ }^{6}$ This mechanism can explain the presentation of our two current patients: the air around the balloon entered through the anastomosis site or biliary tract, and the venous embolism entered the arterial circulation through a transient patent foramen ovale or transpulmonary passage.

To our knowledge, there have been 21 reported cases to date of cerebral embolism complications after an endoscopic procedure, including our current cases (Table 1). ${ }^{7-24}$ The cerebral embolism occurred during or after ERCP in 11 of these cases, and was found during or after another therapeutic esophagogastroduodenoscopy in the remaining 10 cases. Six of the 21 reported patients had undergone major surgery, such as Billroth II operation, total gastrectomy, or Whipple's operation. In addition, the presence of a shunt was evaluated in 17 of these patients, of whom seven did not have a shunt, such as a patent foramen ovale or arteriovenous malformation, including our two present patients.

There are no standard treatments for cerebral air embolisms that occur during or after an endoscopic procedure, and some previous reports ${ }^{12,13}$ have shown that early hyperbaric oxygen therapy has a beneficial effect. Hyperbaric oxygenation therapy may reduce air bubble size, accelerate nitrogen reabsorption, and increase the oxygen content of arterial blood, potentially reducing the ischemia. However, the delay to treatment application has been reported to range from 3 to 48 hours. ${ }^{25}$

Among the five previously reported patients who underwent hyperbaric oxygen therapy, two, including our first case herein, showed full or partial neurologic recovery. The other three patients had poor outcomes, including death or severe neurologic deficit. The remaining 15 patients received high $\mathrm{FiO}_{2}$ therapy or conservative management without hyperbaric oxygen therapy. Of these, six patients died and nine patients survived with or without a neurologic deficit.

In conclusion, we here report two cases of cerebral air embolism as a rare complication of therapeutic endoscopy. Although it is difficult to make this diagnosis because it can be confused with a sedative-related problem, our patients 
Table 1. All Cases of Cerebral Embolism after Gastrointestinal Endoscopy Reported Thus Far

\begin{tabular}{|c|c|c|c|c|c|c|}
\hline Case & Study & Age/sex & $\begin{array}{c}\text { Procedure } \\
\text { Major op history }\end{array}$ & Shunt & НВО & Outcome \\
\hline 1 & Raju et al. $(1998)^{12}$ & $75 / \mathrm{M}$ & EGD with esophageal dilatation (-) & $\mathrm{PFO}$ & Yes & Survived \\
\hline 2 & Akhtar et al. $(2001)^{14}$ & $80 / \mathrm{F}$ & EGD, biopsy (-) & None & No & Survived \\
\hline 3 & Weber et al. $(2003)^{15}$ & $56 / \mathrm{F}$ & $\begin{array}{l}\text { EGD } \\
\text { Ovariectomy }\end{array}$ & $(+)$ & No & Survived \\
\hline 4 & Demaerel et al. $(2003)^{16}$ & $80 / \mathrm{M}$ & $\begin{array}{l}\text { EGD } \\
\text { Total laryngectomy }\end{array}$ & $(+)$ & No & Survived \\
\hline 5 & Rabe et al. $(2006)^{17}$ & $87 / \mathrm{M}$ & ERCP, metal stent insertion (-) & $\mathrm{PFO}$ & No & Survived \\
\hline 6 & Rabe et al. $(2006)^{17}$ & $54 / \mathrm{M}$ & $\begin{array}{l}\text { ERCP, stent dilatation } \\
\text { Billroth II operation }\end{array}$ & $(+)$ & No & Died \\
\hline 7 & Stabil et al. $(2006)^{18}$ & $65 / \mathrm{M}$ & $\operatorname{ERCP}(-)$ & None & No & Died \\
\hline 8 & McAree et al. $(2008)^{13}$ & $69 / \mathrm{M}$ & EGD, biopsy (-) & None & Yes & Died \\
\hline 9 & Goins et al. $(2010)^{19}$ & $72 / \mathrm{F}$ & $\operatorname{ERCP}(-)$ & None & No & Survived \\
\hline 10 & Pandurangadu et al. (2012) & $71 / \mathrm{M}$ & EGD, biopsy (-) & $(+)$ & No & Survived \\
\hline 11 & van Boxel et al. $(2010)^{20}$ & $82 / \mathrm{M}$ & $\operatorname{ERCP}(-)$ & Not mentioned & No & Survived \\
\hline 12 & López et al. $(2010)^{8}$ & $61 / \mathrm{F}$ & EGD, bleeding control (-) & Not mentioned & No & Died \\
\hline 13 & Maccarone et al. $(2011)^{21}$ & $45 / \mathrm{M}$ & $\operatorname{ERCP}(-)$ & $\mathrm{PFO}$ & No & Survived \\
\hline 14 & Efthymiou et al. $(2012)^{9}$ & $62 / \mathrm{F}$ & $\begin{array}{l}\text { ERCP, biopsy } \\
\text { Open cholecystectomy }\end{array}$ & $\mathrm{PFO}$ & No & Survived \\
\hline 15 & Nern et al. $(2012)^{22}$ & $58 / \mathrm{F}$ & $\operatorname{ERCP}(-)$ & $\mathrm{PFO}$ & No & Died \\
\hline 16 & Chavalitdhamrong et al. $(2013)^{23}$ & $66 / \mathrm{M}$ & $\begin{array}{l}\text { ERCP, stent change } \\
\text { Whipple's operation }\end{array}$ & $\mathrm{PFO}$ & No & Died \\
\hline 17 & Zampeli et al. $(2013)^{10}$ & $72 / \mathrm{M}$ & EGD, esophageal dilatation (-) & Not mentioned & No & Died \\
\hline 18 & Pee et al. $(2013)^{11}$ & $84 / \mathrm{F}$ & EGD, esophageal dilatation (-) & Not mentioned & Yes & Died \\
\hline 19 & Rangappa et al. (2009) & $50 / \mathrm{F}$ & $\begin{array}{l}\text { ERCP } \\
\text { Laparoscopic cholecystectomy }\end{array}$ & $\mathrm{PFO}$ & Yes & Died \\
\hline 20 & Present case 1 & $59 / \mathrm{M}$ & $\begin{array}{l}\text { EGD, esophageal dilatation } \\
\text { Total gastrectomy }\end{array}$ & None & Yes & Survived \\
\hline 21 & Present case 12 & $69 / \mathrm{M}$ & ERCP, ERPD (-) & $(+)$ & No & Survived \\
\hline
\end{tabular}

HBO, hyperbaric oxygen therapy; EGD, esophagogastroduodenoscopy; PFO, patent foramen ovale; ERCP, endoscopic retrograde cholangiopancreatography; ERPD, endoscopic retrograde papillary dilatation.

underwent appropriate early management and achieved good outcomes. Physicians should therefore be aware of the risk of cerebral air embolism during or after endoscopic procedures in patients who show cardiopulmonary instability and neurologic symptoms.

\section{Conflicts of Interest}

The authors have no financial conflicts of interest.

\section{REFERENCES}

1. Green J. Complications of gastrointestinal endoscopy [Internet]. London: British Society of Gastroenterology; c2009 [cited 2016 Feb 2]. Available from: http://www.bsg.org.uk/pdf_word_docs/complications.pdf.
2. Silvis SE, Nebel O, Rogers G, Sugawa C, Mandelstam P. Endoscopic complications. Results of the 1974 American Society for Gastrointestinal Endoscopy Survey. JAMA 1976;235:928-930.

3. Gangi S, Saidi F, Patel K, Johnstone B, Jaeger J, Shine D. Cardiovascular complications after GI endoscopy: occurrence and risks in a large hospital system. Gastrointest Endosc 2004;60:679-685.

4. Romagnuolo J, Cotton PB, Eisen G, Vargo J, Petersen BT. Identifying and reporting risk factors for adverse events in endoscopy. Part I: cardiopulmonary events. Gastrointest Endosc 2011;73:579-585.

5. Donepudi S, Chavalitdhamrong D, Pu L, Draganov PV. Air embolism complicating gastrointestinal endoscopy: a systematic review. World J Gastrointest Endosc 2013;5:359-365.

6. Muth CM, Shank ES. Gas embolism. N Engl J Med 2000;342:476-482.

7. Pandurangadu AV, Paul JA, Barawi M, Irvin CB. A case report of cerebral air embolism after esophagogastroduodenoscopy: diagnosis and management in the emergency department. J Emerg Med 2012;43:976979.

8. López JC, Pérez X, Esteve F. Cerebral air embolism during upper endos- 
copy. Endoscopy 2010;42 Suppl 2:E41.

9. Efthymiou M, Raftopoulos S, Antonio Chirinos J, May GR. Air embolism complicated by left hemiparesis after direct cholangioscopy with an intraductal balloon anchoring system. Gastrointest Endosc 2012;75:221223.

10. Zampeli E, Tsagalou E, Kanakakis I, et al. Fatal cerebral air embolism complicating esophageal dilation. Endoscopy 2013;45(Suppl 2 UCTN):E358.

11. Pee L, Basu S, Loganayagam A. Cerebral air embolism: a rare complication following balloon dilation. Endoscopy 2013;45(Suppl 2 UCT$\mathrm{N})$ :E93-E94

12. Raju GS, Bendixen BH, Khan J, Summers RW. Cerebrovascular accident during endoscopy: consider cerebral air embolism, a rapidly reversible event with hyperbaric oxygen therapy. Gastrointest Endosc 1998;47:7073.

13. McAree BJ, Gilliland R, Campbell DM, Lucas JW, Dickey W. Cerebral air embolism complicating esophagogastroduodenoscopy (EGD). Endoscopy 2008;40 Suppl 2:E191-E192.

14. Akhtar N, Jafri W, Mozaffar T. Cerebral artery air embolism following an esophagogastroscopy: a case report. Neurology 2001;56:136-137.

15. Weber MA, Fiebach JB, Lichy MP, Weber R, Schwark C, Grau AJ. Bilateral cerebral air embolism. J Neurol 2003;250:1115-1117.

16. Demaerel P, Gevers AM, De Bruecker Y, Sunaert S, Wilms G. Stroke caused by cerebral air embolism during endoscopy. Gastrointest Endosc 2003;57:134-135.

17. Rabe C, Balta Z, Wüllner U, et al. Biliary metal stents and air embolism: a note of caution. Endoscopy 2006;38:648-650.
18. Stabile L, Cigada M, Stillittano D, et al. Fatal cerebral air embolism after endoscopic retrograde cholangiopancreatography. Acta Anaesthesiol Scand 2006;50:648-649.

19. Goins KM, May JM, Hucklenbruch C, Littlewood KE, Groves DS. Unexpected cardiovascular collapse from massive air embolism during endoscopic retrograde cholangiopancreatography. Acta Anaesthesiol Scand 2010;54:385-388.

20. van Boxel GI, Hommers CE, Dash I, Goodman AJ, Green J, Orme RM. Myocardial and cerebral infarction due to massive air embolism following endoscopic retrograde cholangiopancreatography (ERCP). Endoscopy 2010;42 Suppl 2:E80-E81.

21. Maccarone G, Shakoor T, Ellis B. Air embolism after percutaneous transhepatic biliary drainage and subsequent endoscopic retrograde cholangiopancreatography (ERCP). Endoscopy 2011;43 Suppl 2 UCTN:E399.

22. Nern C, Bellut D, Husain N, Pangalu A, Schwarz U, Valavanis A. Fatal cerebral venous air embolism during endoscopic retrograde cholangiopancreatography: case report and review of the literature. Clin Neuroradiol 2012;22:371-374.

23. Chavalitdhamrong D, Draganov PV. Acute stroke due to air embolism complicating ERCP. Endoscopy 2013;45 Suppl 2 UCTN:E177-E178.

24. Rangappa P, Uhde B, Byard RW, Wurm A, Thomas PD. Fatal cerebral arterial gas embolism after endoscopic retrograde cholangiopancreatography. Indian J Crit Care Med 2009;13:108-112.

25. Blanc P, Boussuges A, Henriette K, Sainty JM, Deleflie M. Iatrogenic cerebral air embolism: importance of an early hyperbaric oxygenation. Intensive Care Med 2002;28:559-563. 